\title{
Quando a recepção já não alcança: os sentidos circulam entre a produção e a recepção ${ }^{1}$
}

\section{Ana Carolina Escosteguy}

\section{Resumo}

0 artigo indica que a perspectiva da recepção constitui potencialmente uma alternativa para alargar a compreensão dos processos comunicacionais que tão frequentemente têm sido estilhaçados, desde que 0 âmbito da recepção não seja tomado como um objeto de estudo circunscrito apenas a esse espaço. Nesse cenário, propõe analisar o processo de constituição de identidades através de um protocolo analítico que destaque as relações entre cultura e poder, isto é, que contemple a dimensão reguladora da cultura exercida tanto na vida social quanto nos modos de ser. É nessa direção que se sugere tomar como uma via teórico-metodológica para equacionar tal problemática a proposição do circuito da cultura, apresentado por Hall (1997) e du Gay e outros pesquisadores (1997), que analisa a circulação de sentidos entre a produção e a recepção.

\section{Palavras-chave}

Identidades. Regulação. Circuito da cultura.

Produção. Recepção.

\section{Ana Carolina Escosteguy | carolad@pucrs.br}

Doutora em Comunicação pela Universidade de São Paulo - USP. Professora do Programa de Pós-Graduação em Comunicação Social da Pontifícia Universidade Católica do Rio Grande do Sul - PUCRS. Pesquisadora do CNPq.

\section{$1 \mathrm{~A}$ proposição}

A constituição, mesmo que recente, de uma tradição de estudos de recepção nos desafia a retomar tal objeto de estudo, devido ao aporte constituído na prática de pesquisa que dá uma nova feição à problemática. Embora dois dos autores mais citados no espectro dos estudos de recepção no meio acadêmico brasileiro, Guillermo Orozco e Jesús Martín-Barbero, insistam em que a recepção não é um momento ou uma etapa do processo comunicativo, a prática de pesquisa que se debruçou sobre esse tema se revela em oposição a esse preceito. Com isso, quero dizer que o espaço da produção, o resultado das práticas aí localizadas, isto é, 0 texto midiático, e o espaço da recepção não mereceram uma atenção equilibrada na grande maioria das pesquisas brasileiras. As condições de produção raramente fizeram parte desses estudos e mesmo o próprio texto é bastante negligenciado em tais investigações².

Dando sequência a outro trabalho (ESCOSTEGUY, 2007), observo que a perspectiva da recepção constitui potencialmente uma alternativa para 
alargar a compreensão dos processos culturais/ comunicacionais que tão frequentemente têm sido estilhaçados $^{3}$, desde que 0 âmbito da recepção não seja tomado como um objeto de estudo circunscrito a apenas esse espaço. Seguindo uma indicação de Ang (1996, p. 52, grifo meu) sobre a necessidade de livrar-se das diversas modalidades de entender as audiências, "0 que conta não é a certeza do conhecimento sobre as audiências, mas um engajamento intelectual, crítico e contínuo, com as variadas formas pelas quais somos constituídos através do consumo da mídia".

Portanto, é adequado indagar-se como 0 pesquisador poderia se posicionar para preservar a dinâmica e particularidades do processo comunicativo. E, com essa meta, investigar a comunicação a partir dos atores sociais, inseridos em determinadas condições sociais concretas, sem perder de vista as tecnologias de comunicação que saturam a vida social e cultural contemporânea.
Não é de menos importância para a constituição de um protocolo analítico que integre produção e recepção, no atual contexto de acelerada expansão tecnológica, a atenção às tecnologias de comunicação envolvidas, pois estas engendram, em certa medida, processos diferenciados de produção de sentidos. Embora Carlón (2004) destaque que há uma resistência em pensar as particularidades dos dispositivos midiáticos no âmbito dos estudos culturais ${ }^{4}$, a dimensão tecnológica está presente tanto na proposição de Hall $^{5}$ (2003a) quanto na de Martín-Barbero.

Especialmente neste último autor, a mediação tecnológica ganha destaque no mapa metodológico proposto. 0 autor alerta que a técnica não pode ser resumida a instrumento, mas é uma dimensão constitutiva das práticas culturais, e que as inovações técnicas estão conectadas com as transformações dos modos de percepção e experiência social. "0 lugar da cultura na sociedade muda quando a mediação

Parte do título deste artigo está inspirado em Sergio Caletti (1992), "La recepción ya no alcanza”, embora minha argumentação se organize em outra direção. Uma primeira versão deste texto, intitulado "Quando a recepção já não alcança: por uma revisão no objeto e método", foi apresentada ao Grupo de Trabalho "Recepção, Usos e Consumo Midiático", do XVII Encontro da Compós, na UNIP, São Paulo, SP, em junho de 2008. Agradeço os comentários de Antonio Fausto Neto, Veneza Mayora, Nilda Jacks, Eneus Trindade e Adriana Braga.

Tomando como ponto de partida o balanço realizado por Jacks e Escosteguy (2005), indico como exemplos que ilustram tal avaliação: na década de 80, Lins da Silva (1985), embora nesse período os pressupostos barberianos ainda não estivessem plenamente incorporados na pesquisa; na década de 90, Jacks ([1993]1999) e Ronsini (1993). É no início dos anos 2000 que se pode observar um esforço em viabilizar uma perspectiva mais integradora desses distintos "momentos" em Lopes et al (2002).

Partes estas que vêm sendo investigadas por setores especializados, apegados a recortes disciplinares, que na maior parte do tempo não interagem dentro do campo da comunicação. Em termos generalizantes, a economia-política da comunicação, os estudos das linguagens dos meios e os de comunicação e cultura.

Tal afirmação ignora o trabalho pioneiro de Raymond Williams (1974).

Ver, por exemplo, o tratamento que Hall dá a especificidade do signo televisivo (2003a, p. 392-398). 
tecnológica da comunicação deixa de ser meramente instrumental para espessar-se, condensar-se e converter-se em estrutural: a tecnologia remete, hoje, não a alguns aparelhos, mas, sim, a novos modos de percepção e de linguagem, a novas sensibilidades e escritas" (MARTÍN-BARBER0, 2006, p. 54).

Apesar disso, concordamos com Carlón (2004) quando conclui que a diferença reside no lugar assumido para elaborar as perguntas. No caso de Carlón (2004, p. 120, grifo meu), "0 estudo da vida social das linguagens", âmbito distinto do ocupado pelos estudos culturais: o estudo dos mecanismos simbólicos presentes nos discursos sociais da mídia que, por sua vez, colaboram na construção da realidade e dos valores culturais dominantes da sociedade contemporânea.

Aparentemente, abre-se, aqui, uma veia conjunta entre os dois posicionamentos convergindo para a incorporação de análises discursivas, à moda de Norman Fairclough e Teun van Dijk. Entretanto, tais métodos têm dificuldade em mostrar as estruturas e interesses sociais a partir dos quais são produzidas as representações, 0 impacto de fatores externos associados, por exemplo, às práticas profissionais que produzem essas representações, bem como uma análise da compreensão da audiência desses mesmos textos (ver PHIL0, 2007). É por essa razão que argumentamos a favor de um método que analise a circulação de sentidos entre a produção e a recepção (ESCOSTEGUY, 2007).

Depois de sugerir que as proposições de Hall (2003a), Johnson (1999) e Martín-Barbero (2003) configuram uma possibilidade teóricometodológica que viabiliza essa visão global e complexa do processo comunicativo, proponho uma complementação: analisar o processo de constituição de identidades culturais através de um protocolo analítico que destaque as relações entre cultura e poder, isto é, que contemple a dimensão reguladora da cultura exercida tanto na vida social quanto nos modos de ser. Isso porque nas primeiras proposições tal dimensão vai perdendo realce para a efetividade política das práticas de (re)interpretação da realidade simbólica dos discursos midiáticos realizadas pelos sujeitos.

Outra das razões para deslocar-se da recepção, como lugar a partir do qual o pesquisador se posiciona para investigar o processo comunicativo, diz respeito à dinâmica que vem sendo instituída pela própria mídia, de esmaecimento das fronteiras entre produção e recepção através do chamamento cada vez mais crescente dos receptores para participarem da esfera da produção. Assim, eles se transformam em protagonistas dos mais variados textos ${ }^{6}-$ dos reality shows às cartas de leitores, dos materiais jornalísticos centrados no protagonismo de 
sujeitos ordinários aos blogs na internet. Isso altera as regras, as lógicas, os processos e os produtos na medida em que a produção das mensagens passa gradativamente para as mãos dos receptores (FAUSTO NETO, 2008). A inclusão dos receptores na esfera da produção tem relação, entre outros fatores, com a chamada convergência tecnológica, o que, por sua vez, tem estreita vinculação com as singularidades das tecnologias de comunicação em uso. Sendo assim, essas novas dinâmicas têm profunda repercussão na constituição das identidades dos atores sociais.

Ao trazer a questão das identidades para a comunicação, afastamo-nos de discussões teóricas mais abrangentes, tais como análises filosóficas e psicanalíticas sobre o tema. Trata-se de uma compreensão mais limitada e recortada por modos específicos de construção identitária, localizados em determinadas atividades sociais - em especial relacionadas à mídia, num meio social particular. Isso não significa abster-se da contribuição teórica, ao contrário. Somente podemos pensar tal problemática num contexto de erosão das identidades, entendidas até certo momento como entidades estáveis, coesas e unificadas. Pensá-la em termos mais instrumentais e práticos é descrever e analisar processos específicos de formação identitária que, no nosso caso, são constituídos pela avassaladora presença das distintas redes de tecnologias de comunicação.
À primeira vista, até este ponto, nada há de novidade nesta proposição (ver, por exemplo, JACKS, 1996). No entanto, ressalvas são necessárias ao modo como tal tema estudo das identidades vinculadas à mídia - vem sendo tratado pelo prisma da recepção. Genericamente, pelo reiterado destaque aos usos e apropriações dos textos midiáticos pelo receptor e pela referência constante a tais práticas culturais e sociais que vinculam 0 âmbito individual com 0 social, sem a necessária observação das limitações impostas pela estruturação social mais geral e até mesmo pelos próprios textos midiáticos. 0 que se omite, portanto, são as relações de poder e a regulação das esferas do pessoal e do privado pela própria mídia. Em outros termos, há um apagamento da relação inversa - dos textos midiáticos e das lógicas culturais sobre os receptores.

É nessa direção que sugiro tomar como uma via teórico-metodológica para equacionar tal problemática a proposição do circuito da cultura (du GAY, HALL et al. 1997; HALL, 1997). Justifico essa opção na medida em que esse protocolo integra os espaços da produção e da recepção/consumo, enfraquecendo a premissa de "autonomia relativa" entre eles. Ao invés disso, observa-se que a relação entre cultura e economia e vice-versa fica cada vez mais entranhada, fenômeno que não se pode desatender dado ao crescente movimento de monopolização do espaço cultural por empresas transnacionais. 


\section{0 s antecedentes}

Antes de apresentar esse protocolo teóricometodológico, considero apropriado retomar 0 modelo da codificação/decodificação do discurso televisivo, de Hall (2003a), pois aí já se encontram pistas importantes para construir uma visão global e integrada do processo comunicativo ${ }^{7}$. E, com certeza, existem conexões entre esse modelo e posteriormente a proposição do circuito da cultura.

Assim como Martín-Barbero foi tomado na América Latina como o deflagrador dos estudos de recepção, Hall ocupou espaço semelhante com o modelo da codificação/decodificação. Contudo, ambos, com modalidades distintas, estavam tratando do processo comunicativo como um todo, destacando-se as instâncias aí envolvidas. 0 modelo de Hall (2003a) está fundado na ideia de comunicação como estrutura sustentada por uma articulação entre momentos distintos - produção, circulação, distribuição, consumo - na qual cada um tem condições próprias de existência. Como eles estão articulados entre si, devem ser registrados e analisados um em relação ao outro, sendo que cada momento é necessário para 0 todo, mas nenhum antecipa o próximo.

Se você vai falar de articulação, você tem de identificar os momentos isolados para poder falar sobre o que está relacionado com o quê. Mas eu não falo como se esses momentos tivessem algum caráter auto-suficiente. Portanto, é sempre a produção e o consumo em uma relação. (HALL, 2003b, p. 359)
Dado a influência do estruturalismo nos estudos culturais e, em especial na reflexão de Hall, é importante destacar o que ele mesmo reconhece como "o avanço de Althusser não apenas em termos de sua insistência na 'diferença' [...] mas em termos da necessidade de pensar a unidade com a diferença" (HALL, 2003c, p. 163, grifo do autor).

Destaca-se, na sua concepção a articulação entre as mensagens, o lugar onde estas têm origem, com suas respectivas rotinas de produção, e 0 trabalho interpretativo da parte dos receptores, embora cada uma dessas práticas conserve "sua distinção e [...] modalidade específica, suas próprias formas e condições de existência". Reside aí um insight produtivo para as pesquisas empíricas na medida em que essa premissa indica a existência de circunstâncias particulares para emergência de uma dada situação e é nesse espaço que sua descrição adquire relevância. No entanto, esse duplo aspecto de conexão e autonomia relativa foi descuidado pelos estudos brasileiros de recepção.

Embora o modelo proponha uma homologia com as estruturas da produção econômica dentro da sociedade capitalista - produção, circulação, consumo, reprodução -, privilegia a formatextual do produto midiático, em detrimento da forma-mercadoria. Isso porque está fundado num aporte semiótico. Mesmo assim, Hall (2003a) tensiona premissas que têm sua origem 
pautada em tal abordagem ao contemplar a complexa estruturação midiática e 0 dia a dia da produção, bem como as condições sociais e materiais da recepção.

A proposta do autor tenta preservar a dinâmica do processo, desafiando a ideia de uma hierarquia entre produção e recepção e de uma correspondência obrigatória entre elas, embora admita que é a produção que constrói a mensagem e que o processo de produção de sentido aí se inicia. Nas condições de produção, conta tanto a estrutura institucional, as rotinas de produção, a interferência de ideologias profissionais e hipóteses sobre a audiência quanto o meio social de onde são retirados "assuntos, tratamentos, agendas, eventos, equipes, imagens da audiência, 'definições de situação' de outras fontes e outras formações discursivas" (HALL, 2003a, p. 389), forças que, também, constituem a audiência. Contudo, vale destacar que a instância da produção também é entendida como discursivamente constituída.

Sua proposição fala do modo como os sentidos são construídos no processo de produção $0^{8} \mathrm{e}$ recepção das formas culturais, portanto, não basta analisar o espaço da produção, mas também 0 âmbito da recepção deve fazer parte da agenda de investigação. "0 consumo ou a recepção da mensagem da televisão é, assim, também ela mesma um 'momento' do processo de produção no seu sentido mais amplo" (HALL, 2003a, p. 390). Na direção contrária ao paradigma dominante na época em que circulou o artigo comentado, Hall (2003a) assinala que as práticas de recepção não podem ser simplesmente vistas em termos comportamentais, mas são ordenadas por estruturas de compreensão, bem como produzidas por relações econômicas e sociais.

[...] é sob a forma discursiva que a circulação do produto se realiza, bem como sua distribuição para diferentes audiências. Uma vez concluído, 0 discurso deve então ser traduzido - transformado de novo - em práticas sociais, para que 0 circuito ao mesmo tempo se complete e produza efeitos. Se nenhum 'sentido' é apreendido, não pode haver 'consumo'. Se 0 sentido não é articulado em prática, ele não tem efeito (HALL, 2003a, p. 388).

Ao mesmo tempo em que reivindica que o sentido dos textos midiáticos não está determinado pelo emissor e que a mensagem não é transparente, sendo potencialmente transformável em mais de uma configuração, Hall (2003a, p. 396) alerta que tal polissemia é sempre estruturada. "Toda sociedade ou cultura tende [...] a impor suas classificações do mundo social, cultural e político. Essas classificações constituem uma ordem social dominante, apesar de esta não ser nem unívoca nem incontestável".

Associado a essa ideia, assinala a existência de sentidos dominantes ou preferenciais que, 
embora não sejam sistemas fechados nem fixos, dão vazão a leituras preferenciais - uma das possíveis posições-tipo de decodificação indicadas por ele. Assim, a introdução de tal posicionamento modera a ideia de que a sociedade é um campo aberto de discursos e que todas as leituras têm o mesmo valor analítico. Outra indicação importante, mas raramente seguida na pesquisa do espaço da recepção.

Essas premissas revelam que 0 autor não adere a uma posição determinista, mas também não exclui a presença de uma força dominante. Nesse contexto, diz: "desejo apostar em uma noção de poder e de estruturação no momento de codificação que todavia não apague todos os outros possíveis sentidos" (HALL, 2003b, p. 366). Assim, as audiências se movem entre a posição preferencial ou hegemônica-dominante'; a posição negociada e a posição de oposição. Esta última posição resiste à ordem social dominante $\mathrm{e}$ é considerada por Hall (2003a, p. 402) como "um dos momentos políticos mais significativos", pois ela instaura a instabilidade na hegemonia e pode conduzir à ruptura ou mudança.

0 que esse modelo deixa ver é que os sentidos precisam entrar no domínio das práticas sociais e que não há como considerar que tenham completado o circuito comunicativo, sem antes terem sido decodificados. Dessa forma, tanto 0 "receber o texto" (espaço da recepção/ decodificação) quanto o "imputar sentido" (espaço da produção/codificação) são práticas de produção de sentido. Tratando-se de um circuito, esse processo de produção de sentido está sempre articulado a outro momento, sendo possível iniciar a investigação em qualquer lugar, embora ainda exista certo destaque para a produção. Contudo, Hall sempre deixou claro que a mídia prioriza determinadas narrativas e sentidos em detrimento de outros e que, portanto, a recepção não é um espaço livre de pressões. Além disso, nesse protocolo, observase determinada centralidade na mídia, no caso, a televisão, de onde emana a produção social de sentido.

\section{0 circuito da cultura}

A partir das suas primeiras análises sobre 0 Thatcherismo que causaram tanta polêmica, sobretudo, na esquerda britânica, Hall vem defendendo que qualquer ordem econômica somente funciona quando é constituída por uma dimensão discursiva, isto é, que "o econômico" é operacionalizado ou se torna 'real' dentro da dimensão cultural. Esse princípio é reforçado por Paul du Gay (2000, p. 114), parceiro importante na mesma empreitada teórica:

Os processos e práticas econômicas, em toda sua pluralidade, tanto se nos referimos às técnicas de administração para conduzir a reestruturação dos negócios, às estratégias contemporâ- 
neas de publicidade de mercadorias e serviços quanto às interações diárias entre empregadores da área de serviços e seus clientes, dependem do sentido para seu efeito e têm condições culturais particulares de existência.

Da política à economia, incluindo o espaço dos negócios e dos empreendimentos comerciais, todos estão envolvidos com questões culturais. Na esfera da política, a análise de Hall tratava de associar o projeto de Thatcher a um programa de reformas que dizia respeito a atitudes e valores do cidadão, mas também a "mudanças culturais" nas instituições. Já, no mundo empresarial, fala-se insistentemente em "mudança de cultura" como parte de programas administrativos para alcançar mais eficiência e competitividade. Levando em conta tais situações, não seria possível atribuir à cultura um papel secundário.

É esse processo que revela a centralidade da cultura, hoje. Nesse cenário é que um ponto de vista sobre a reflexão da importância da cultura na vida social se afirma sem recorrer a uma lógica dicotômica do tipo cultura versus economia. Ao invés disso, borram-se as fronteiras entre elas, bem como a hierarquia. Sendo assim, a cultura

[...] não pode mais ser estudada como uma variável sem importância, secundária e dependente em relação ao que faz o mundo mover-se; tem de ser vista como algo fundamental, constitutivo, determinando tanto a forma como o caráter deste movimento, bem como a sua vida interior (HALL, 1997, p. 23).
A ela é atribuído tanto um lugar na estrutura empírica real, isto é, uma ocorrência na sociedade, quanto é usada "para transformar nossa compreensão, explicação e modelos teóricos do mundo" (HALL, 1997, p.16). Neste último caso, assume um caráter epistemológico, diz respeito a um lugar a partir do qual posicionar-se para pensar a sociedade. Aqui, localiza-se a mudança de registro que vem sendo chamada de "virada cultural", na qual não há experiência ou artefato que de alguma forma não seja passível de associações simbólicas. Decorre daí, também, a ideia de que a cultura não está acima nem da economia nem da política, mas permeia tudo.

No que diz respeito ao primeiro âmbito - ou seu caráter substantivo, nos termos de Hall (1997) e, também, do texto coletivo de du Gay e outros investigadores (1997) - está a globalização e seus efeitos sobre o meio social, seja constituindo a vida local e cotidiana seja configurando a formação de identidades. Se, por um lado, essa ideia refere-se a um âmbito macro de funcionamento da sociedade, também, pode-se observar sua repercussão, importância e caráter formativo na "vida interior", isto é, seu papel constitutivo na configuração de identidades e da própria subjetividade.

Porém, antes de adentrar nessa dimensão específica do circuito - da identidade -, é necessário reconstituí-lo rapidamente para bem da clareza. Em primeiro lugar, ressalta- 
se que 0 circuito da cultura ${ }^{10}$ é composto por

diversos momentos - Produção, Consumo,

Representação, Identidade e Regulação - onde

os sentidos/significações são produzidos. Existe

aí uma relação interna de um processo com 0

outro, contudo não há forma de predeterminar

como essas relações são constituídas, pois elas

são variáveis e conjunturais, permanecendo 0

insight do modelo anterior (HALL, 2003a) de que

existem condições e circunstâncias particulares

que configuram situações específicas. Entretanto,

diferentemente da primeira proposição, aqui, não

há indício de privilégio para a Produção como

aquele espaço que, em princípio, poderia explicar

o sentido atribuído a um determinado artefato ou

produto. É a combinação desses momentos, numa

dada articulação, que propicia sua compreensão.

Lembre que isso é um circuito. Não conta onde você inicia, dado que se tem de fazer toda a volta, antes do estudo estar completo. E mais: cada parte tomada do circuito reaparece na próxima. Então, tendo iniciado na Representação, as representações tornam-se um elemento na parte seguinte, isto é, de como as identidades são construídas. E assim sucessivamente. Nós separamos essas partes do circuito em diferentes seções, mas no mundo real elas continuamente se sobrepõem e entrelaçam de modo complexo e contingente. Contudo, elas são as partes que tomadas em conjunto compõem o que nós en- tendemos por um 'estudo cultural' de um objeto particular (du GAY, 1997, p. 4).

De toda forma, o espaço da Produção extrapola o entendimento de que se incluiria aí apenas a produção, entendida de modo convencional como procedimentos necessários para criação propriamente dita de um artefato/produto. Em síntese, abarca também as distintas narrativas que se associam à invenção desses mesmos produtos. A investigação de du Gay e seus colaboradores (1997, p. 43) sobre o walkman facilita a compreensão desse espaço: "trata-se de entender as distintas práticas utilizadas na produção do walkman e no modo pelo qual tais práticas que estão disseminadas e são representadas revelando valores, crenças e padrões específicos de trabalho". Nessa dimensão, estariam tanto as narrativas pessoais quanto aquelas que circulam na mídia e se associam seja à criação de um artefato material, seja à de um produto cultural.

Dado que, nesse circuito, as estratégias de Produção estão sempre em diálogo com 0 Consumo, inclusive se sobrepondo, nessa mesma investigação os estudiosos identificam quatro eixos sobre tal conexão: exposta no presente artigo. Por essa razão, o fato desse estudo não ter realizado pesquisa empírica junto aos respectivos públicos não invalida as balizas teóricas e o programa de pesquisa implícito na proposta do circuito. Nessa direção, associo-me com Johnson e outros autores (2004, p. 42) quando diz: "É necessário, então, que todo projeto de pesquisa investigue cada momento do circuito? (Esta é uma questão que é frequentemente lançada por preocupados pesquisadores iniciantes.) Deve um estudo sobre talk-show, por exemplo, sempre incluir pesquisa de sua audiência e vida cotidiana? Isso não é possível em toda pesquisa e nem todos os questionamentos propostos exigem isso, mas uma consciência teórica [grifo do próprio autor] dos demais momentos e métodos deveria configurar o desenho da pesquisa e a apresentação das evidências - sempre." 
Em primeiro lugar, ao considerar como 0 walkman está dirigido a um imaginado consumidor jovem. Em segundo, indicando como o nome do aparelho foi guiado por suposições a respeito das respostas dos consumidores. Terceiro, levando em conta aspectos de marketing e, por último, destacando como a Sony tentou monitorar e obter feedback sobre a atividade de consumo (du GAY et al, 1997, p. 52).

Vale, ainda, destacar que o Consumo como momento específico, na presente proposição, pressupõe a existência de agência humana. Isso implica em incorporar também o que as pessoas vão fazer com tais artefatos ou produtos após sua circulação no mercado. Ou seja, esse momento está afinado com o exame do papel das práticas de consumo na produção de - novos - sentidos/significações ou, em outros termos, com a observação dos "atores em ação". É dessa forma que a produção e 0 consumo não se configuram como esferas separadas, mas sim são mutuamente constitutivas.

Assume particular importância no protocolo 0 papel central das representações - diz respeito ao momento da Representação - postas em circulação que organizam e regulam as mais diversas práticas sociais. A Representação é entendida como a associação de significações a um determinado artefato/produto, desse modo, o sentido não surge do "próprio objeto", mas da forma como ele é representado pelas linguagens. Parte-se do pressuposto que a realidade existe fora da linguagem, mas é mediada por e através da linguagem - e o que nós podemos saber e dizer tem de ser produzido no e através do discurso.
'Experimentamos' o mundo graças a e através dos sistemas de representação da cultura. A experiência é o produto de nossos códigos de inteligibilidade, de nossos esquemas de interpretação. Em consequência, não existe nenhuma experiência fora das categorias da representação ou do discurso (HALL, 2003b, p. 360).

E, quando são examinadas as representações e seu impacto na constituição das subjetividades dos atores sociais, já nos deslocamos para outro momento - o da Identidade. "É por meio dos significados produzidos pelas representações que damos sentido à nossa experiência e àquilo que somos" (WOODWARD, 2000, p. 17); desse modo, a partir do momento que adotamos certas posições, construídas a partir dessas significações, "nossas identidades" vão sendo formadas.

Por que é estratégico esse momento no circuito cultural? A identidade, como uma posição em construção que não se cristaliza no tempo e no espaço, sugere uma possibilidade de contestação do poder ou "a emergência de novas posições e de novas identidades" (WOODWARD, 2000, p. 19). Contudo, tomar a questão da identidade como tópico nodal não equivale a centralizar a visão nem nas possibilidades de resistência nem nos modos de contestação. É tanto um desafio a uma visão liberadora quanto a uma posição conformista.

A razão disso está na explicitação ou na incorporação de outro momento do circuito cultural, a Regulação, que evidencia que as relações entre cultura e poder são conflituosas e incontornáveis. Conforme Hall (1997), este 
responde à necessidade de pensar sobre diversas questões postas neste âmbito. Em primeiro lugar, a esfera da cultura é governada seja pela tendência à regulação, seja pela desregulação. Ela pode estar associada, no primeiro caso, ao Estado e, no segundo, ao mercado. Em ambas as situações, a cultura é regulada, afetada por pressões econômicas e de grupos, bem como de estruturas de poder. Ela está em íntima associação com o modo de produção econômica e as formas de consumo, mas não só!

Ao mesmo tempo em que existe esse "governo da cultura", há a ocorrência de um movimento inverso: a "regulação através da cultura". Hall (1997) identifica três formas desse tipo de regulação: a normativa, que guia a ação humana mediante normas associadas a convenções existentes na cultura; a segunda que classifica nossas ações segundo os padrões culturais vigentes; e, por fim, aquela que incide diretamente na constituição das subjetividades e, portanto, das identidades. Esta forma de regulação busca que 0 sujeito internalize as condutas, normas e regras, regulando-se a si mesmo. É nesse sentido que se efetiva o poder da mídia, penetrando nos modos de ser.

\section{Comentários finais}

Depois de apresentar os dois protocolos analíticos, para terminar, comenta-se provisoriamente a matéria, deixando para aprofundar esta reflexão em outra ocasião. 0 modelo da codificação/decodificação pressupõe um objeto de estudo claramente delimitado às conexões específicas entre a esfera da produção e recepção, operacionalizadas pela mídia. E é 0 próprio Hall que reconhece na sua proposição tal limite: "Se ele é de alguma serventia, para hoje ou mais tarde, é pelo que sugere. Sugere uma abordagem, abre novas questões, mapeia o terreno. Mas é um modelo que tem de ser trabalhado, desenvolvido e mudado" (HALL, 2003b, p. 356). Uma das questões centrais trata da incorporação do espaço da recepção como um lugar onde os sentidos em circulação adquirem valor social e efetividade política. Reside aí sua validade ainda hoje $\mathrm{e}^{11}$.

Sem abandonar essa esfera de ação, o circuito cultural oferece a possibilidade de construir um objeto de estudo que compreende a cultura como um aspecto das práticas sociais que constituem as formações sociais. Ou seja, a pesquisa é norteada pelo entendimento de como os processos culturais se tornam efetivos na articulação de um todo social. Nessa direção, além da premissa de articulação entre os diversos momentos que constituem o circuito da cultura, uma de suas vantagens em relação ao modelo anterior é a incorporação da Regulação, onde 0 poder assume uma posição central e a ação do sujeito obrigatoriamente passa a ser pensada em relação aos distintos processos de controle 
social - ausentes na maioria dos estudos que se restringem à recepção. É claro que, também, essa abordagem apresenta riscos. 0 principal deles é permanecer atrelado a uma concepção de sujeito completamente auto-regulado.

É aqui que, ainda, a vocação política dos estudos culturais se manifesta, introduzindo a problemática da identidade. De um lado, já dissemos em outro lugar (ESCOSTEGUY, 2003) que a importância em discutir tal tema diz respeito à sua conexão com a agência. Contudo, Hall (2000, p. 105) alerta que perceber tal importância não implica em adotar uma noção de sujeito como "autor centrado da prática social". De outro, tomar a identidade como momento crucial no circuito da cultura é um forte indicativo para livrar-se de uma referência estrita à recepção/receptor. Na abordagem em discussão, trata-se de um processo muito mais amplo e complexo que diz respeito aos atores sociais e à configuração de modos de ser.

\section{Referências}

ANG, Ien. Living room wars: rethinking media audiences for a postmodern world. Londres: Routledge, 1996.

CARLÓN, Mario. Sobre la desatención del dispositivo: Estudios Culturales. In: Sobre lo televisivo: dispositivos, discursos y sujetos. Buenos Aires: La Crujía, 2004.

CALETTI, Sergio. La recepción ya no alcanza. In: CORTEZ, Carlos; SOLIS, Beatriz; NUÑEZ, Luis (orgs.) Generación de conocimientos y formación de comunicadores. Peru: FELAFACS, 1992.
COIR0, Ana Luisa. A síndrome do protagonista: uma abordagem cultural às personagens dos espetáculos de realidade da mídia. 2008. Tese (Doutorado em Comunicação)- Programa de Pós-Graduação em Comunicação Social, Pontifícia Universidade Católica do Rio Grande do Sul, Porto Alegre, 2008.

Du GAY, Paul. Representing 'globalization': Notes on the discursive orderings of economic life.In: GILROY, P., GROSSBERG, L. e MCROBBIE, A. (orgs.) Without guarantees: In honour of Stuart Hall. Londres: Verso, 2000. ; NEGUS, Keith; HALL, Stuart; JANES, Linda; MACKAY, Hugh. Doing Cultural Studies: the story of the Sony Walkman. Londres: Sage, 1997.

ESCOSTEGUY, Ana Carolina. Circuitos de cultura/ circuitos de comunicação: um protocolo analítico de integração da produção e da recepção. Revista Comunicação, Mídia e Consumo - ESPM/SP, vol. 4, n 11, p. 115-135, nov. 2007. Anotações para pensar o sujeito nos estudos culturais. Animus, Santa Maria, vol. II, n.1, jan-jun. 2003.

FAUSTO NETO, Antonio. Fragmentos de uma 'analítica' da midiatização. Matrizes, São Paulo, n. 2, p. 89-105, abr. 2008.

FREIRE, João. Reinvenções da resistência juvenil - os estudos culturais e as micropolíticas do cotidiano. Rio de Janeiro: Mauad X, 2007.

HALL, Stuart. Codificação/Decodificação. In:

Da diáspora: Identidades e mediações culturais. Belo Horizonte: UFMG, 2003a, p. 387-404. Reflexões sobre o modelo de codificação/ descodificação: uma entrevista com Stuart Hall. In: . Da diáspora: identidades e mediações culturais. Belo Horizonte: UFMG, 2003b, p. 353-386. Significação, repesentação, ideologia Althusser e os debates pós-estruturalistas. In: Da diáspora: Identidades e mediações culturais. Belo Horizonte: UFMG, 2003c, p. 159-198. 
The centrality of culture: notes on the cultural revolutions of our time. In: THOMPSON, Kenneth (org.). Media and Cultural Regulation. Londres: Sage, 1997. p. 207-238. (Tradução brasileira: A centralidade da cultural: notas sobre as revoluções culturais do nosso tempo, Revista Educação e Realidade, Porto Alegre, vol. 22, n. 2, p. 15-46, jul/dez 1997.)

Quem precisa de identidade? In: SILVA,

Tomaz Tadeu da (org.) Identidade e diferença. Vozes, Petrópolis, 2000.

JACKS, Nilda. Querência: cultura regional como mediação simbólica. Porto Alegre: Editora da Universidade, 1999. (Originalmente Tese de Doutorado, ECA/USP, 1993) ; ESCOSTEGUY, Ana Carolina. Comunicação e receção. São Paulo: Hacker, 2005.

Televisión, recepción e identidad: cuestiones e imbricaciones. In: OROZCO, G. (coord.) Miradas

latinoamericanas a la televisión. Mexico: Universidad Iberoamericana, 1996.

JOHNSON, Richard. What is cultural studies anyway? In: STOREY, John (org.), What is Cultural Studies? A reader. London: Arnold, 1996 [1986-87]. p.75-114. (Tradução brasileira:0 que é, afinal, estudos culturais? In: SILVA, Tomas Tadeu da (org.). 0 que é, afinal, estudos culturais? Belo Horizonte: Autêntica, 1999.)

JOHNSON, R.; CHAMBERS, D.; RAGHURAN, P.; TINCKNELL, E. The practice of cultural studies.

Londres: Sage, 2004.

LOPES, Maria Immacolata; BORELLI, Silvia; RESENDE, Vera. Vivendo com a telenovela: mediações, recepção e teleficcionalidade. São Paulo: Summus, 2002.

LINS DA SILVA, Carlos Eduardo. Muito além do jardim botânico: um estudo sobre a audiência do Jornal Nacional da Globo entre trabalhadores. São Paulo: Summus, 1985. (Originalmente apresentada como Tese de Doutorado, ECA/USP, 1984).
MARTÍN-BARBER0, Jesús. Pistas para entre-ver meios e mediações. In: Dos meios às mediações: comunicação, cultura e hegemonia. Rio de Janeiro: UFRJ, 2003. Prefácio à $5^{\mathrm{a}}$ edição castelhana incluída na reimpressão.

Tecnicidades, identidades, alteridades: mudanças e opacidades da comunicação no novo século. In: MORAES, Denis (org.) Sociedade mediatizada. Rio de Janeiro: Mauad, 2006.

PHIL0, Greg. Puede el analisis del discurso explicar satisfactoriamente el contenido de los media y de las practicas periodisticas? Journalism Studies, New York, vol. 8, n. 2, 2007.

ROJEK, Chris. Stuart Hall. Londres: Polity Press, 2003. RONSINI, Veneza. Cotidiano rural e recepção da televisão: 0 caso de Três Barras. 1993. Dissertação (Mestrado em Comunicação)- Escola de Comunicações e Artes, Universidade de São Paulo, São Paulo, 1993.

SAINTOUT, Florência; FERRANTE, Natalia (orgs.). Y la recepción? Balance crítico de los estudios sobre el público. Buenos Aires: La Crujía, 2006.

WILLIAMS, Raymond. Television: technology and cultural form. Hanover: Wesleyan University Press, 1974.

WO0DWARD, Kathryn. Identidade e diferença: uma introdução teórica e conceitual. In: SILVA, Tomaz Tadeu da (org.). Identidade e Diferença. Vozes, Petrópolis, 2000. 
When reception does not reach anymore: meanings circulate between production and reception

\section{Abstract}

The article offers a discussion about the limits of reception studies. Instead of this thread of research, the author engages with the proposal of study cultural identities. This involves an approach that has been developed in a series of studies based first in Hall's encode/decode model and finally in cultural circuits (du Gay, Hall et al, 1997; Hall, 1997). The main advantage of this method is to consider the sphere of regulation, rethinking the relations between culture and power, level that it is usually forgotten within reception studies.

\section{Keywords}

Identities. Regulation. Cultural circuits.

Production. Reception.

\section{Cuando la recepción ya no alcanza: los sentidos circulan entre la producción y la recepción}

\section{Resumen}

El artículo señala que la perspectiva de la recepción se constituye en una alternativa para entender los procesos comunicacionales de modo más complejo. De toda forma, afirma que tomar la recepción como un punto de vista no es equivalente a transformarla en objeto de estudio. Propone, entonces, otra alternativa: analizar el proceso de constitución de las identidades con un protocolo analítico que dé importancia a las relaciones entre cultura y poder, esto es, que contemple la dimensión reguladora de la cultura ejercida tanto en la vida social como en los modos de ser. Es en esa dirección que sugiere tomar como una vía teórico-metodológica la propuesta del circuito cultural, presentada por Hall (1997) y du Gay y otros investigadores (1997).

\section{Palabras clave}

Identidades. Regulación. Circuito de la cultura. Producción. Recepción. 


\section{Expediente}

A revista E-Compós é a publicação científica em formato eletrônico da Associação Nacional dos Programas de Pós-Graduação em Comunicação (Compós). Lançada em 2004, tem como principal finalidade difundir a produção acadêmica de pesquisadores da área de Comunicação, inseridos em instituições do Brasil e do exterior.
E-COMPÓS I www.e-compos.org.br I E-ISSN 1808-2599

Revista da Associação Nacional dos Programas de Pós-Graduação em Comunicação. Brasília, v.12, n.1, jan./abr. 2009.

A identificação das edições, a partir de 2008 passa a ser volume anual com três números.

\section{CONSELHO EDITORIAL}

\section{Afonso Albuquerque}

Universidade Federal Fluminense, Brasil

Alberto Carlos Augusto Klein

Universidade Estadual de Londrina, Brasi

Alex Fernando Teixeira Primo

Universidade Federal do Rio Grande do Sul, Brasil

\section{Alfredo Vizeu}

Universidade Federal de Pernambuco, Brasil

Ana Carolina Damboriarena Escosteguy

Pontifícia Universidade Católica do Rio Grande do Sul, Bras

Ana Silvia Lopes Davi Médola

Universidade Estadual Paulista, Brasil

André Luiz Martins Lemos

Universidade Federal da Bahia, Brasil

Ângela Freire Prysthon

Universidade Federal de Pernambuco, Brasil

Antônio Fausto Neto

Universidade do Vale do Rio dos Sinos, Brasil

Antonio Carlos Hohlfeldt

Pontifícia Universidade Católica do Rio Grande do Sul, Brasil

Arlindo Ribeiro Machado

Universidade de São Paulo, Brasil

César Geraldo Guimarães

Universidade Federal de Minas Gerais, Brasil

Cristiane Freitas Gutfreind

Pontifícia Universidade Católica do Rio Grande do Sul, Brasil

Denilson Lopes

Universidade Federal do Rio de Janeiro, Brasil

Eduardo Peñuela Cañizal

Universidade Paulista, Brasi

Erick Felinto de Oliveira

Universidade do Estado do Rio de Janeiro, Brasil

Francisco Menezes Martins

Universidade Tuiuti do Paraná, Brasil

Gelson Santana

Universidade Anhembi/Morumbi, Brasi

Hector Ospina

Universidad de Manizales, Colômbia

leda Tucherman

Universidade Federal do Rio de Janeiro, Brasil

Itania Maria Mota Gomes

Universidade Federal da Bahia, Brasil

Janice Caiafa

Universidade Federal do Rio de Janeiro, Brasil

Jeder Silveira Janotti Junior

Universidade Federal da Bahia, Brasil

\section{João Freire Filho}

Universidade Federal do Rio de Janeiro, Brasil

John DH Downing

University of Texas at Austin, Estados Unidos

José Luiz Aidar Prado

Pontifícia Universidade Católica de São Paulo, Brasil

José Luiz Warren Jardim Gomes Braga

Universidade do Vale do Rio dos Sinos, Brasil

Juremir Machado da Silva

Pontifícia Universidade Católica do Rio Grande do Sul, Brasil

Lorraine Leu

University of Bristol, Grã-Bretanha

Luiz Claudio Martino

Universidade de Brasília, Brasil

Maria Immacolata Vassallo de Lopes

Universidade de São Paulo, Brasil

Maria Lucia Santaella

Pontifícia Universidade Católica de São Paulo, Brasil

Mauro Pereira Porto

Tulane University, Estados Unidos

Muniz Sodre de Araujo Cabral

Universidade Federal do Rio de Janeiro, Brasil

Nilda Aparecida Jacks

Universidade Federal do Rio Grande do Sul, Brasil

Paulo Roberto Gibaldi Vaz

Universidade Federal do Rio de Janeiro, Brasil

Renato Cordeiro Gomes

Pontifícia Universidade Católica do Rio de Janeiro, Brasil

Ronaldo George Hela

Universidade do Estado do Rio de Janeiro, Brasil

Rosana de Lima Soares

Universidade de São Paulo, Brasil

Rossana Reguillo

Instituto Tecnológico y de Estudios Superiores do Occidente, México

Rousiley Celi Moreira Maia

Universidade Federal de Minas Gerais, Brasil

Sebastião Carlos de Morais Squirra

Universidade Metodista de São Paulo, Brasi

Simone Maria Andrade Pereira de Sá

Universidade Federal Fluminense, Brasil

Suzete Venturelli

Universidade de Brasília, Brasil

Valério Cruz Brittos

Universidade do Vale do Rio dos Sinos, Brasil

Veneza Mayora Ronsini

Universidade Federal de Santa Maria, Brasil

Vera Regina Veiga França

Universidade Federal de Minas Gerais, Brasil
COMISSÃO EDITORIAL

Ana Gruszynski I Universidade Federal do Rio Grande do Sul, Brasil

Rose Melo Rocha I Escola Superior de Propaganda e Marketing, Brasil

CONSULTORES AD HOC

Alberto Schneider I Visitante Tokyo University

Alexandre Rocha da Silva I Universidade Federal do Rio Grande do Sul, Brasil

Fernanda Bruno I Universidade Federal do Rio de Janeiro, Brasil

Ida Stumpf I Universidade Federal do Rio Grande do Sul, Brasil

Kati Caetano I Universidade Tuiuti do Paraná, Brasil

Laura Cánepa I Universidade Anhembi Morumbi, Brasi

Malena Contrera I Universidade Paulista, Brasil

Sandra Gonçalves I Universidade Federal do Rio Grande do Sul, Brasil

Vicente Gosciola I Universidade Anhembi Morumbi, Brasil

REVISÃO DE TEXTO E TRADUÇÃo I Everton Cardoso

EDITORAÇ̃̃o ELETRÔNICA I Raquel Castedo
COMPós I www.compos.org.br

Associação Nacional dos Programas de Pós-Graduação em Comunicação

Presidente

Erick Felinto de Oliveira

Universidade do Estado do Rio de Janeiro, Brasil erickfelinto@uol.com.br

Vice-presidente

Ana Silvia Lopes Davi Médola

Universidade Estadual Paulista, Brasil

asilvia@faac.unesp.br

Secretária-Geral

Denize Correa Araújo

Universidade Tuiuti do Paraná, Brasil

denizearaujo@hotmail.com 